Full length Article

\title{
Biochemical characterization and low-resolution SAXS structure of an exo- polygalacturonase from Bacillus licheniformis
}

\author{
Danilo Elton Evangelista ${ }^{\mathrm{a}}$, Evandro A. de Araújo ${ }^{\mathrm{a}}$, Mario Oliveira Neto ${ }^{\mathrm{b}}$, \\ Marco Antonio Seiki Kadowaki ${ }^{a}$, Igor Polikarpov ${ }^{a, *}$ \\ ${ }^{a}$ Instituto de Física de São Carlos, Universidade de São Paulo, Avenida Trabalhador Sãocarlense 400, CEP 13566-590 São Carlos, SP, Brazil \\ b Departmento de Física e Biofísica, Institudo de Biociências, Universidade Estadual Paulista “Júlio de Mesquita Filho" (UNESP), CEP 18618-970 Botucatu, São Paulo, \\ Brazil
}

\section{A R T I C L E I N F O}

\section{Keywords:}

Pectinase

Exo-polygalacturonase

Biochemical characterization

Thermal and $\mathrm{pH}$ stability

SAXS molecular envelope

\begin{abstract}
A B S T R A C T
Among the structural polymers present in the plant cell wall, pectin is the main component of the middle lamella. This heterogeneous polysaccharide has an $\alpha-1,4$ galacturonic acid backbone, which can be broken by the enzymatic action of pectinases, such as exo-polygalacturonases, that sequentially cleave pectin from the nonreducing ends, releasing mono or di-galacturonic acid residues. Constant demand for pectinases that better suit industrial requirements has motivated identification and characterization of novel enzymes from diverse sources. Bacillus licheniformis has been used as an important source for bioprospection of several industrial biomolecules, such as surfactants and enzymes, including pectate lyases. Here we cloned, expressed, purified, and biochemically and structurally characterized an exo-polygalacturonase from $B$. licheniformis (BlExoPG). Its low-resolution molecular envelope was derived from experimental small-angle scattering data (SAXS). Our experimental data revealed that BlExoPG is a monomeric enzyme with optimum $\mathrm{pH}$ at 6.5 and optimal temperature of approximately $60{ }^{\circ} \mathrm{C}$, at which it has considerable stability over the broad $\mathrm{pH}$ range from 5 to 10 . After incubation of the enzyme for $30 \mathrm{~min}$ at $\mathrm{pH}$ ranging from 5 to 10 , no significant loss of the original enzyme activity was observed. Furthermore, the enzyme maintained residual activity of greater than $80 \%$ at $50{ }^{\circ} \mathrm{C}$ after $15 \mathrm{~h}$ of incubation. BlExoPG is more active against polygalacturonic acid as compared to methylated pectin, liberating mono galacturonic acid as a unique product. Its enzymatic parameters are $V_{\max }=4.18 \mu \mathrm{M} . \mathrm{s}^{-1}, K_{m}=3.25 \mathrm{mgmL}^{-1}$ and $k_{\text {cat }}=2.58 \mathrm{~s}^{-1}$.
\end{abstract}

\section{Introduction}

The plant cell wall is built up of a number of intimately intertwined structural polymers forming complex heterogeneous structures. The middle lamella is mostly composed of pectin, a heterogeneous polysaccharide formed of methyl esterified galacturonic acid units, linked by $\alpha-1,4$ glycoside bonds [1]. Methyl groups of the backbone chain are removed by the enzymatic action of pectin methylesterase (PME) and the $\alpha-1,4$ glycosidic bonds are cleaved by the catalytic action of two different classes of pectinases: pectate lyases (PL, EC 4.2.2.) that use a trans-elimination reaction for cleavage, thus releasing unsaturated sugars; and the polygalacturonases (PGs), which employ hydrolytic reactions leading to release of saturated sugars [1,2]. Among PGs, the endo-PG (EC 3.2.1.15) randomly hydrolyzes internal sites of the pectin chain, while the exo-PG promotes a sequential cleavage from non-reducing ends cleaving off mono (EC 3.2.1.67) or di-galacturonic acid residues (EC 3.2.1.82) [2]. Pectinases have a wide range of industrial applications, e.g., in extraction and clarification of fruit juices, oil extraction, pretreatment of wastewaters containing pectin, and retting and degumming of crop fibers, to list a few $[1,3,4]$. Some of the applications, such as fruit juice clarification and winemaking, require acid pectinases that are generally obtained from fungi $[1,3]$. On the other hand, degumming and retting of natural fibers and textile scouring demand applications of alkaline pectinases, which are commonly obtained from bacterial sources $[1,3]$.

Driven by constant biotechnological demands in pectinolytic enzymes, there is a need for identification and characterization of novel pectinases with biochemical properties that could be useful in industrial settings. Bacillus licheniformis has been reported as an important microbial producer of several industrial enzymes. This microorganism is a gram-positive, mesophilic bacterium, commonly found in the soil, growing at temperatures between 15 and $68{ }^{\circ} \mathrm{C}$ [5]. Superior performance in secretion of alkaline serine protease transformed $B$. licheniformis in one of the most important bacterial sources of these enzymes,

\footnotetext{
* Corresponding author.

E-mail address: ipolikarpov@ifsc.usp.br (I. Polikarpov).
} 
produced at an industrial scale [6]. Furthermore, B. licheniformis is also widely used as an industrial strain for surfactant production $[7,8]$. $B$. licheniformis is also being used as a microbial source for other industrially relevant enzymes, such as cellulases, xylanases [9-11] and pectinases [12-15]. Here we cloned, expressed, purified and biochemically characterized a novel exo-polygalacturonase (BlExoPG) from $B$. licheniformis and determined its small-angle X-ray scattering low-resolution molecular envelope in solution.

\section{Materials and methods}

\section{Cloning, expression and purification}

The BlExoPG open reading frame (ORF; GenBank access number: AAU42338.1AAU42338.1) was cloned into expression vector pETTRXA-1a/LIC as previously described [16]. The resulting plasmid was built to express BlExoPG fused at the N-terminal region to a histidine affinity-tag to facilitate purification and thioredoxin to increase yield of soluble protein and contained a cleavage site for Tobacco etch virus (TEV) protease. The E. coli DH5 $\alpha$ cells were transformed by electroporation in a propagation step. Next, the purified plasmid was used to heat shock transform $E$. coli Rosetta cells rendering the BlExoPG expression strain. The protein expression was performed at $37^{\circ} \mathrm{C}$ for $5 \mathrm{~h}$ followed by an incubation at $18^{\circ} \mathrm{C}$ for $24 \mathrm{~h}$ in ZYM-5052 medium [17] containing lactose as an inducer agent. Subsequently, the cells were harvested by centrifugation at $2.000 \times g$ for $45 \mathrm{~min}$ and $4{ }^{\circ} \mathrm{C}$, suspended in a lysis buffer ( $50 \mathrm{mM}$ Tris- $\mathrm{HCl} \mathrm{pH} 8.0,300 \mathrm{mM} \mathrm{NaCl}, 5 \mathrm{mM}$ imidazole, 5\% glycerol, $1 \mathrm{mM}$ PMSF, $1 \mathrm{mM}$ DTT and $25 \mu \mathrm{g} \cdot \mathrm{mL}^{-1}$ of lysozyme) complemented with $1 \times$ protease inhibitor cocktail (SigmaFast $^{\mathrm{TM}}$, Sigma) and incubated at a room temperature for $40 \mathrm{~min}$. The cells were disrupted by sonication on ice bath using a 550 Sonic Dismembrator Sonifier (Fisher Scientific). After centrifugation $(6,000 \times g$, $30 \mathrm{~min}$ at $4{ }^{\circ} \mathrm{C}$ ) the target protein was purified from supernatant fraction using two steps of nickel affinity chromatography, one before and one after TEV proteolysis. In a first purification step, the recombinant protein (with a molecular mass of about $65 \mathrm{kDa}$ ) was eluted using $100 \mathrm{mM}$ Tris- $\mathrm{HCl}$ buffer, $\mathrm{pH}$ 8.0, $300 \mathrm{mM} \mathrm{NaCl}$ and $100 \mathrm{mM}$ imidazole. Trace amounts of imidazole were removed by dialysis in the same buffer. The purified protein was incubated with $3 \mathrm{mg} \mathrm{mL}^{-1}$ of TEV protease during $48 \mathrm{~h}$ at $4{ }^{\circ} \mathrm{C}$. In a second purification step, recombinant protein devoid of the fusion Hist-Trx-tag and with apparent molecular mass of about $50 \mathrm{kDa}$ was eluted using $100 \mathrm{mM}$ potassium phosphate $\mathrm{pH} 7.0,150 \mathrm{mM} \mathrm{NaCl}$ and $65 \mathrm{mM}$ imidazole. To ensure the sample purity, a third purification step was performed by running the protein samples on Superdex ${ }^{\text {TM }} 200$ prep grade 16/60 (GE) molecular exclusion column using $100 \mathrm{mM}$ potassium phosphate $\mathrm{pH} 7.0$ in $150 \mathrm{mM} \mathrm{NaCl}$. To estimate the BlExoPG mass, a calibration chromatography curve for the gel filtration column was assembled using standard proteins with the known molecular masses. The BlExoPG protein samples were concentrated to $1.5 \mathrm{mg} \mathrm{mL}^{-1}$ using a $30 \mathrm{kDa}$ Amicon Concentrator (Milipore) at $2500 \times g$ and stocked at $4{ }^{\circ} \mathrm{C}$. The sample purity was confirmed by $12 \%$ SDS-PAGE stained with Comassie blue.

\section{Enzymatic assays}

The enzymatic activity was quantitatively determined by the DNS method that measures the reducing end-groups of saccharides [18]. All experiments were conducted in triplicate. Specific activity of the enzyme was tested using five different substrates (Sigma): polygalacturonic acid, pectin from citrus fruit (20-34\% esterified), pectin from apple (75\% esterified), carboxymethylcellulose (CMC) and xylan. Since the BlExoPG showed highest enzymatic activity against non-methylated substrate, the following biochemical characterization was conducted using polygalacturonic acid. The reaction consisted of $2.2 \mu \mathrm{M}$ enzyme, $1 \%(\mathrm{w} / \mathrm{v})$ polygalacturonic acid and $100 \mathrm{mM}$ buffer in $50 \mu \mathrm{L}$ final volume and was incubated for $20 \mathrm{~min}$. The reaction was
Table 1

Biochemical characterization of BlExoPG.

\begin{tabular}{llll}
\hline Substrates (1\%) & Rel. activity (\%) & Additives (4 mM) & Rel. activity (\%) \\
\hline poly-GalA & 100 & Control & 100 \\
Citrus pectin & 20 & $\mathrm{~K}^{+1}$ & 96.2 \\
Apple pectin & 2 & $\mathrm{Mg}^{+2}$ & 91.9 \\
CMC & 0 & $\beta-\mathrm{ME}$ & 89.7 \\
Xylan & 0 & $\mathrm{Li}^{+2}$ & 88.0 \\
& & $\mathrm{DTT}^{+2}$ & 83.3 \\
& $\mathrm{Ca}^{+2}$ & 74.7 \\
& $\mathrm{Ni}^{+2}$ & 73.5 \\
& $\mathrm{Mn}^{+2}$ & 68.5 \\
& $\mathrm{Fe}^{+3}$ & 64.6 \\
& $\mathrm{Cu}^{+2}$ & 30.4 \\
& $\mathrm{Co}^{+2}$ & 36.0 \\
& & $\mathrm{Fe}^{+2}$ & 11.76 \\
& Additives $(\mathbf{0 . 1} \%)$ & \\
& Triton $\times 100$ & 96.6 \\
& Tween 20 & 87.4 \\
& SDS & 24.2 \\
\hline
\end{tabular}

stopped with $100 \mu \mathrm{L}$ of DNS reagent, boiled at $100{ }^{\circ} \mathrm{C}$ for $5 \mathrm{~min}$ and immediately cooled on ice for $1 \mathrm{~min}$. The absorbance was measured at $540 \mathrm{~nm}$ using the MultiSkan Spectrum (Thermo Scientific) equipment and the absorbance values converted to relative activity.

The optimum temperature was determined in potassium phosphate buffer at $\mathrm{pH} 7.0$ in a temperature range from 40 to $80^{\circ} \mathrm{C}$. The optimum $\mathrm{pH}$ was determined at $60^{\circ} \mathrm{C}$ by varying $\mathrm{pH}$ of sodium citrate/glycine/ sodium phosphate buffer from 2 to 10 . To assess the enzyme thermal stability, it was pre-incubated at 50,60 and $70{ }^{\circ} \mathrm{C}$ during different periods of time at the optimum $\mathrm{pH}$. To evaluate the enzyme stability at different $\mathrm{pHs}$, it was pre-incubated in a $\mathrm{pH}$ range of 2 to 10 using phosphate/borate/acetate buffer at the optimum temperature for $30 \mathrm{~min}$. The residual activity was assessed under the optimum $\mathrm{pH}$ and temperature conditions. In addition, the enzyme activity was analyzed in the presence of 15 different additives (Table 1). Kinetic parameters $V_{\max }, K_{m}$ and $k_{c a t}$ of the enzyme were determined using D-(+)-galacturonic acid monohydrate (GalA) (Sigma) for building of a standard concentration curve. The reactions were performed under the optimal conditions, varying the substrate concentration from 0.1 to $9.0 \mathrm{mg} \mathrm{mL}^{-1}$.

All the obtained data were analyzed using GraphPad Prism software (version 5.0). To define the values of optimal $\mathrm{pH}$ and temperature the "Sum of two Gaussians" analysis was applied, and "Michaelis-Menten" and " $k_{\text {cat }}$ " analyses were executed to determine the kinetic parameters.

\section{Enzymatic cleavage pattern}

Thin layer chromatography (TLC) method [19] was used to analyze the soluble products generated by the enzyme cleavage. The reactions were performed with $0.1 \%$ polygalacturonic acid under the optimum conditions for enzymatic activity. The samples were collected after 0.5 , 1.5 and $3 \mathrm{~h}$ of incubation and centrifuged at $13,000 \times g$ for $5 \mathrm{~min}$. After centrifugation at $13,000 \times g$, the reaction supernatants were deposited at a TLC silica gel $60 \mathrm{~F}_{254}$ sheet (MERCK).

Sample separation was performed by ten times alternation between two running solutions (solution A: 1-butanol: 2-propanol: acetic acid: water (7:5:2:4); and solution B: 1-butanol: acetic acid: water (4:5:1)). The dried sheet was sprayed with $5 \%$ sulfuric acid: ethanol (v/v) and heated at $105{ }^{\circ} \mathrm{C}$ for $10 \mathrm{~min}$. To independently confirm and to extend the TLC results, more sensitive HPAEC analyses were also performed. The HPAEC system (ICS-5000, Dionex), equipped with a CarboPAC1 analytical column ( $250 \mathrm{~mm} \times 2 \mathrm{~mm}$ i.d., Dionex) was used. The flow rate was set at $0.5 \mathrm{~mL} \mathrm{~min}^{-1}\left(30^{\circ} \mathrm{C}\right)$. The injection volume was $1 \mu \mathrm{L}$ and the elution was performed using two steps: a linear gradient from 0.05 to $0.7 \mathrm{M}$ sodium acetate in $0.1 \mathrm{M} \mathrm{NaOH}$ for $65 \mathrm{~min}$ followed by a different linear gradient up to $1 \mathrm{M}$ sodium acetate for $10 \mathrm{~min}$. GalA and 
Tri-GalA (Sigma) were used as standards in all experiments.

Chromatography-coupled small-angle X-ray scattering data and structural analyses

Size-exclusion chromatography-coupled small-angle X-ray scattering (SEC-SAXS) data were collected at the B21 beamline of the Diamond Light Source Synchrotron (Didcot, UK). The data were measured using a Pilatus2 $\mathrm{M}$ detector (Dectris) set to cover momentum transfer within $4.014 \mathrm{E}-03 \AA^{-1}<\mathrm{q}<4.07 \mathrm{E}-01 \AA^{-1}$ range $(\mathrm{q}=4 \pi$ $\sin \theta / \lambda$, where $2 \theta$ is the scattering angle).

Prior to data collection, the protein samples were centrifuged at $17,000 \times g$ for $2 \mathrm{~h}$ at $4{ }^{\circ} \mathrm{C}$, then loaded onto a $4.8 \mathrm{~mL} \mathrm{KW}-403$ column (Shodex) equilibrated with a buffer solution ( $50 \mathrm{mM}$ Tris- $\mathrm{HCl} \mathrm{pH} 8.0$, $150 \mathrm{mM} \mathrm{NaCl}, 5 \% \mathrm{w} / \mathrm{v}$ glycerol) coupled to an Agilent 1200 HPLC system. Scattering data were collected in-line mode at B21 beamline at Diamond Light Source. During the SAXS measurements the sample $(40 \mu \mathrm{L})$ passed through an in-vacuum quartz capillary of $1.6 \mathrm{~mm}$ path length at a flow rate of $0.16 \mathrm{~mL} \mathrm{~min}^{-1}$ at a controlled temperature of $25{ }^{\circ} \mathrm{C}$. The SAXS data frames were collected at three seconds exposure intervals and the buffer frames used for the background subtracted SAXS were collected after 1.5 column volume. The scattering image frames were spherically averaged, scaled and merged using in-house software and ScÅtter pipelines (Diamond Light Source, Didcot, UK, http://www.bioisis.net/tutorial/9).

The radius of gyration $\left(R_{g}\right)$ was estimated by two methods: first, using the Guinier equation $-I(q)=I(0) \cdot \exp \left[\left(-q^{2} \cdot R_{g}^{2}\right) / 3\right]$, q. $R_{g}<1.3$ [20-22], and then using ScÅtter (Diamond Light Source, Didcot, UK); the same was done with the pair distribution of the particle, $P(r)$, and the maximum dimension, $D_{\max }$.

Twenty one independent "dummy atom" models (DAMs) were restored by the $a b$ initio procedure implemented in DAMMIF [23], where the DAMSTART model was improved with the software DAMMIN [24], both included in the ATSAS suite [25]. The best model was superimposed with the computed homology model using SUPCOMB software [26]. Based on reported crystallographic structures as well as the homology model, the X-ray scattering profiles were computed using FOXS, and the discrepancy between experimental and theoretical SAXS curves was quantified using the minimized FoXS $\chi$-parameter [27]. SAXS_MoW was used to evaluate molecular weight of the protein in solution [28].

\section{Results and discussion}

\section{Expression, purification and molecular mass calculation}

BlExoPG gene was successfully cloned into the pETTRXA-1a/LIC expression vector and used to transform $E$. coli Rosetta cells. The enzyme was overexpressed as a $65-\mathrm{kDa}$ protein fused to the Hist-Trx-tag (Fig. 1A). First, the fused protein was purified by $\mathrm{Ni}^{+2}$ affinity chromatography by eluting with $100 \mathrm{mM}$ imidazole. After Hist-Trx-tag removal with TEV protease, the $50 \mathrm{kDa}$ non-fused protein was collected in $65 \mathrm{mM}$ imidazole in a second step of $\mathrm{Ni}^{+2}$ affinity chromatography. This molecular weight is close to the theoretical molecular mass of the enzyme estimated from its amino acid sequence ( $48.14 \mathrm{kDa})$. Next, a gel filtration chromatography step was performed to ensure the sample purity and to estimate the protein molecular weight in solution. The protein was eluted as a unique peak (Fig. 1B). The molecular mass calculated from the experimental calibration curve corresponds to a protein with molecular mass of approximately $54 \mathrm{kDa}$ (Fig. 1C), which indicates that BlExoPG exists in monomeric form in solution.

\section{Enzymatic characterization}

BlExoPG exhibits enzymatic activity only for the pectic substrates with no activity against CMC, or xylan detected (Table 1). The highest specific activity was observed for polygalacturonic acid (poly-Gal), followed by approximately 5 times lower activity for citrus pectin and
A

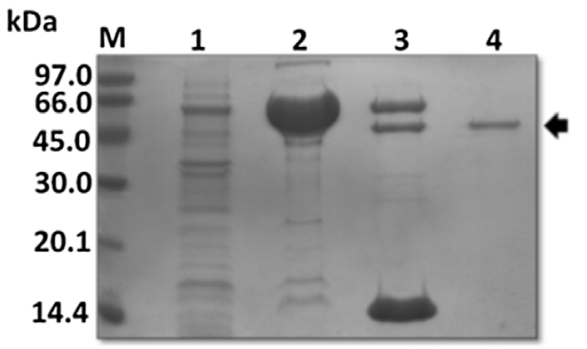

B

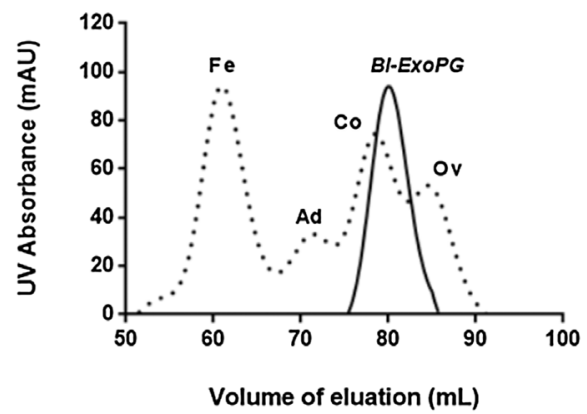

C

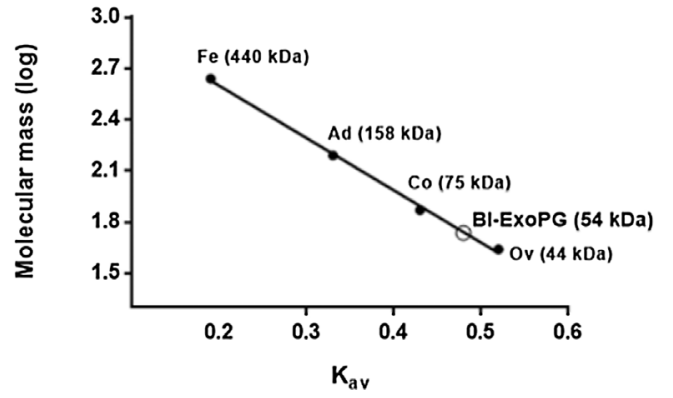

Fig. 1. Expression, purification and native PAGE characterization of BlExoPG. A) SDSPAGE showing purification steps of BlExoPG; 1: total soluble protein; 2: BlExoPG fused to thioredoxin and His-tag ( $65 \mathrm{kDa}$, approximately) purified by $\mathrm{Ni}^{+2}$ affinity chromatography using $100 \mathrm{mM}$ imidazole for elution; 3: BLExoPG after cleavage of thioredoxin and His-tag by TEV protease; 4: BlExoPG ( $50 \mathrm{kDa}$, approximately) purified by $\mathrm{Ni}^{+2}$ affinity chromatography with $65 \mathrm{mM}$ imidazole followed by molecular exclusion chromatography. B) Exclusion molecular chromatography profile containing ferritin (440 kDa), aldolase (158 kDa), conalbumin $(75 \mathrm{kDa})$ and ovalbumin $(44 \mathrm{kDa})$ molecular markers overlaid with BlExoPG elution peak. C) The BlExoPG elution profile shows that it is a monomeric protein with the molecular weight of approximately $54 \mathrm{kDa}$, as estimated from our experimental calibration line.

50 times lower specific activity for apple pectin. The enzyme specificity for non-methylated pectin is a common feature for the PGs and it is well known that the removal of methyl-groups from the esterified pectin, by the enzymatic action of pectin methylesterase, increases the affinity of PGs for the substrate [29-31].

Next, we evaluated the influence of metal ions and detergents on BlExoPG enzymatic activity (Table 1). No positive effects were observed for any of the additives used in our experiments, instead, all caused some decrease in the enzyme activity. Major detrimental effects were observed for SDS (loss of $76 \%$ in enzymatic activity) and for bivalent cations, mainly $\mathrm{Fe}^{+2}, \mathrm{Co}^{+2}$ and $\mathrm{Cu}^{+2}$ which caused losses of $88 \%, 70 \%$ and $64 \%$ of enzymatic activity, respectively. These results are in line with the behavior of enzymatic activity of other PGs. For example, PG from Pleurotus ostreatus lost 29.4\%, 33\%, 48.2\%, 56.3\% and $95.8 \%$ in activity in the presence of $\mathrm{Ni}^{+2}, \mathrm{Ca}^{+2}, \mathrm{Cu}^{+2}, \mathrm{Mg}^{+2}$, and $\mathrm{Fe}^{+3}$, respectively [32]. Exo-PG from Bacillus KSM-P576 showed stability in $5 \mathrm{mM} \beta$-mercaptetanol, but lost, $69 \%, 28 \%$ and $10 \%$ of its activity upon addition of $\mathrm{Cu}^{+2}, \mathrm{Ni}^{+2}$ and SDS [33]. Notably, the latter enzyme gained $60 \%, 36 \%, 31 \%, 18 \%$ and $16 \%$ when $\mathrm{Mg}^{+2}, \mathrm{Mn}^{+2}, \mathrm{Fe}^{+2}, \mathrm{Ca}^{+2}$ and $\mathrm{Fe}^{+3}$ were added to the reaction [33]. 


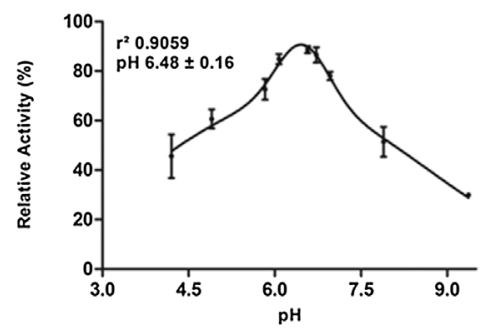

B

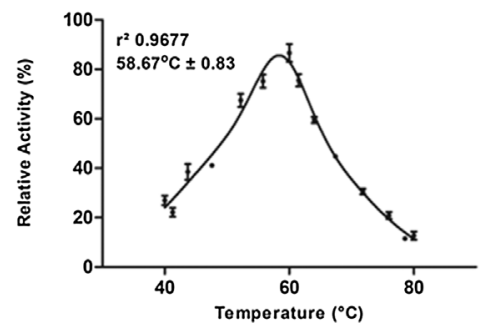

C

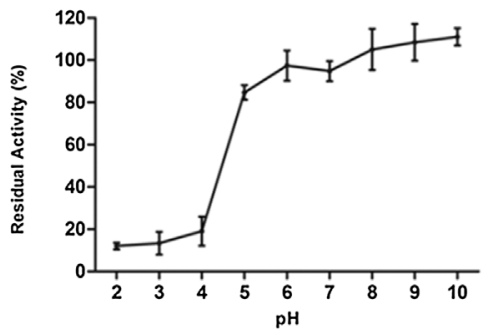

D

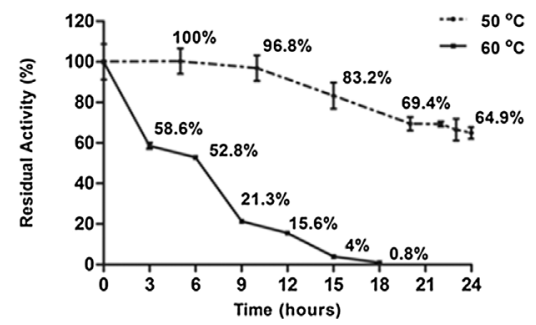

Fig. 2. Enzymatic activity. BlExoPG has the highest activity at (A) $\mathrm{pH}$ 6.5 and (B) $60{ }^{\circ} \mathrm{C}$. (C) The enzyme is stable in a pH range from 5 to 10 . (D) The thermostability assays show that at the optimal temperature and $\mathrm{pH}$, the enzyme half-life is approximately $6 \mathrm{~h}$; and the complete inactivation was observed after $18 \mathrm{~h}$. At $50{ }^{\circ} \mathrm{C}$, the enzyme maintained about $80 \%$ of its original activity after $15 \mathrm{~h}$; and even after $24 \mathrm{~h}$ its activity was over $60 \%$ of its maximum activity.
By varying $\mathrm{pH}$ we observed that BlExoPG has optimum catalytic activity at $\mathrm{pH} 6.5$, while retaining $60 \%$ of maximum activity at $\mathrm{pH} 5$ and $50 \%$ at $\mathrm{pH} 8$ (Fig. 2A). In general, fungal pectinases are acidic enzymes, while bacterial pectinases are alkaline [1,3,13,33], but $B l$ ExoPG has slightly acidic $\mathrm{pH}$ behavior, retaining considerable activity at neutral and slightly alkaline pHs. Similar behavior has been previously observed for two thermostable exo-PGs from Thermotoga maritima, with optimal pHs of 6.4 [34] and 6.0 [35]; and for thermostable PG from Sporotrichum thermophile with $\mathrm{pH}$ optimum at 7.0 [36]. BlExoPG optimal temperature is close to $60{ }^{\circ} \mathrm{C}$ (Fig. 2B). It maintains $65 \%$ of the maximum activity at $50{ }^{\circ} \mathrm{C}$ and about $30 \%$ at $70{ }^{\circ} \mathrm{C}$. BlExoPG kinetic parameters $V_{\max }=4.18 \mu \mathrm{M} \mathrm{s}^{-1}, K_{m}=3.25 \mathrm{mg} \mathrm{mL}^{-1}$ and $K_{\text {cat }}=2.58 \mathrm{~s}^{-1}$ were defined under the optimal conditions described above, using poly-GalA as a substrate.

Stability over a wide $\mathrm{pH}$ range and for prolonged periods of time at high temperatures are important enzymatic properties for biotechnological applications. Therefore, we assessed enzyme stability by measuring the residual enzymatic activity after incubation at different $\mathrm{pHs}$ at $60{ }^{\circ} \mathrm{C}$ for $30 \mathrm{~min}$ (Fig. 2C). Activity dropped below $20 \%$ after exposure to $\mathrm{pH} 2$ to 4 and to $84.6 \%$ at $\mathrm{pH} 5$. From pH 6 to 10 the enzyme kept the original activity without any significant loss, revealing that BlExoPG is highly stable at pH 5 to 10 .

To extend our stability analyses, we measured the enzyme residual activity for prolonged periods of time at elevated temperatures (Fig. 2D). At $70^{\circ} \mathrm{C}$, the enzyme lost all enzymatic activity after $20 \mathrm{~min}$ of incubation. At the optimal temperature $\left(60^{\circ} \mathrm{C}\right)$, the enzymatic activity decreased by half $(52.8 \%)$ after $6 \mathrm{~h}$; decreased to $21.3 \%$ after $9 \mathrm{~h}$ and complete inactivation was observed after $18 \mathrm{~h}$. At $50{ }^{\circ} \mathrm{C}$, the enzyme preserved high residual activity $(83.2 \%)$ after $15 \mathrm{~h}$ and, even after $24 \mathrm{~h}, 64.9 \%$ of activity was maintained, thus demonstrating that $B l E x o P G$ tolerates this high temperature condition for extended periods of time before complete inactivation occurs.

To evaluate the products liberated by the BlExoPG enzymatic action, we submitted these to TLC and HPAEC analyses. The TLC analysis showed a unique band corresponding to monogalacturonic acid under all three reaction times analyzed (Fig. 3, insert). The soluble products from the $3 \mathrm{~h}$ reaction sample were also analyzed by HPAEC, resulting in a single chromatographic peak corresponding to GalA monomer (Fig. 3). Thus, both TLC and HPAEC analyses consistently confirm that $B l E x o P G$ is indeed an exo-polygalacturonase classified as EC 3.2.1.67, releasing mono galacturonic acid as the single product of the enzymatic reaction.

Most of the commercially available pectinases are produced by

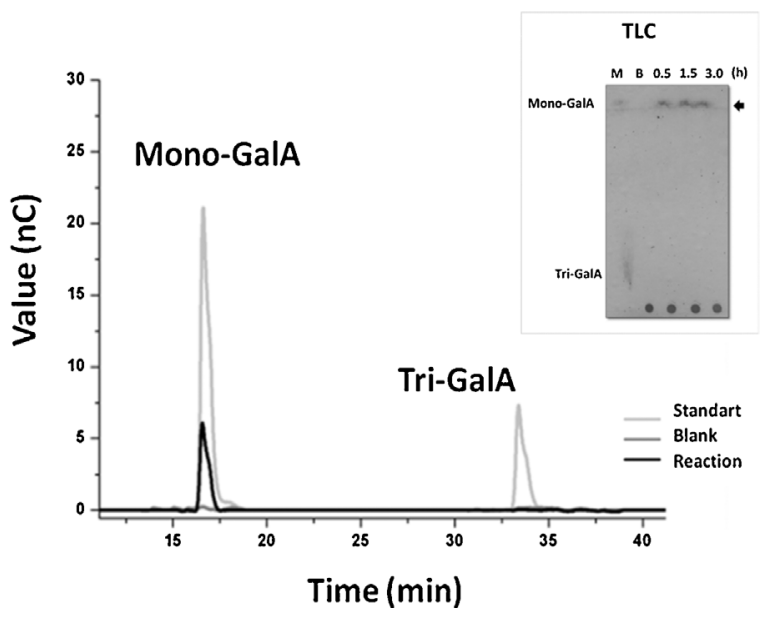

Fig. 3. BlExoPG cleavage pattern. An image of TLC plate is given as an insert at the right side of the figure. M: molecular marker with a standard solution containing mono and triGalA; B: 3-h-incubation at the absence of enzyme; and the following spots show products liberated after $0.5,1.0$ and $3.0 \mathrm{~h}$ of enzymatic action. The reactions were carried out under optimum conditions for BlExoPG enzymatic activity. HPAEC chromatogram of the liberated products after 3 -h of reaction is given at the left side. The results consistently show that the monogalacturonic acid is the unique product of BlExoPG enzymatic action.

Table 2

Industrial pectinases.

\begin{tabular}{llll}
\hline Product & Organism & Manufacturer & Reference \\
\hline Klerzyme 150 & A. niger & DSM Food Specialties & {$[46]$} \\
Pectinase PE-500 & A. niger & Boli Bioproducts & {$[47]$} \\
Pectinase & A. niger & Parchem & {$[48]$} \\
Pectinase & A. niger & Biocon & {$[49]$} \\
Polygalacturonase & A. niger & Biocon & {$[50]$} \\
Macerozyme R-10 & Rhizopus sp. & Duchefa Biochemie B.V & {$[51]$} \\
Pectate lyases & Bacillus sp. & Novozymes & {$[38]$} \\
Pectate lyases & B. licheniformis & Novozymes & {$[39]$} \\
\hline
\end{tabular}

fungi, notably Aspergillus niger and also Rhizopus sp (Table 2). These fungal enzymes are acidophilic and have activity in the $\mathrm{pH}$ range 2.0 to 6.5. On the other hand, in the paper and textile industrial sectors, alkaline pectinases have been used as a more cost effective and ecologically friendly alternative to conventional caustic scouring processes [37]. Some of the industrial alkaline pectate lyases are produced by 

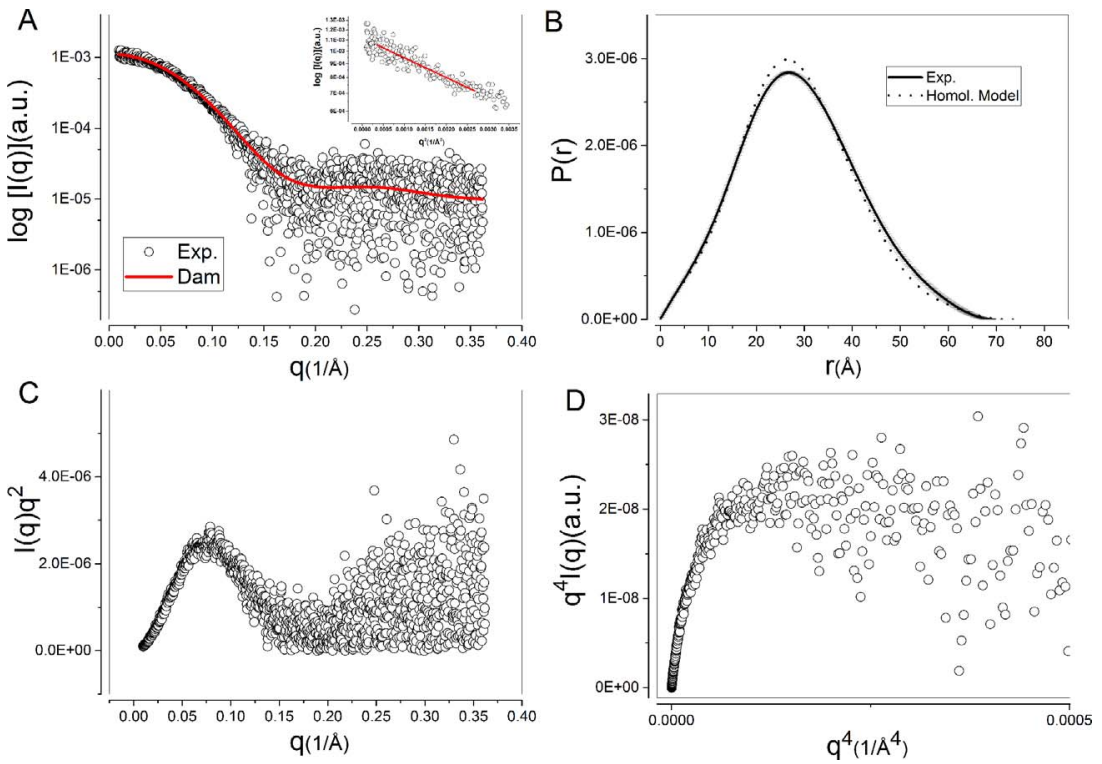

Fig. 4. SAXS data. (A) BlExoPG experimental and modeled scattering curves. BlExoPG experimental SAXS curve (open black circles) is superimposed with the theoretical scattering curve calculated from the restored low-resolution DAM model shown as a red line. The plot in the insert shows Guinier fitting of the experimental SAXS data. The linear fit to the $q$-intermediate data used to calculate $R_{g}$ is shown as a red line. (B) $P(r)$ functions determined from the experimental scattering data with errors bars is shown as a black solid line and $P(r)$ functions determined from the computed scattering curve for the homology atomic model of BlExoPG is given as a black dashed line. (C) Dimensionless Kratky plot indicates the expected position of the maxima for globular-like compact particles. (D) The Porod-Debye plot of the SAXS data. (For interpretation of the references to colour in this figure legend, the reader is referred to the web version of this article.)
Bacillus species, including $B$. licheniformis $[38,39]$, therefore, BlExoPG presents itself as a potential candidate for biotechnological and industrial applications, which require neutral or alkaline enzymes. Complete pectin deconstruction requires cooperative action of the different attack mechanisms of the diversified classes of pectinases, such as PME, PL, endo-PG and exo-PG. Thus, besides being useful in its own right, BlExoPG can be combined with, for example, the available $B$. licheniformis pectate lyases to synergistically improve pectin processing.

\section{SEC-SAXS data collection and structural analysis}

In order to determine the shape and molecular structure of the $B l$ ExoPG, we analyzed BlExoPG using the SEC-SAXS approach to gain a better understanding of the enzymatic mechanisms and its molecular behavior in solution. The samples were monodisperse and monomeric, as suggested by the linearity of Guinier plots of the scattering data (Fig. 4A), and by BlExoPG molecular mass estimated from the scattering data ( $\sim 44 \mathrm{kDa}$, Table 3$)$. We analyzed the initial $q$-region of the scattering curves using the Guinier approximation $\left(\log (I(q))\right.$ versus $\left.q^{2}\right)$, which exhibited a linear correlation, indicative of a globular shape (Fig. 4A, insert). The Guinier radius of gyration $\left(R_{g}\right)$ for each scattered frame remained constant within the experimental errors in the range of protein concentrations used in the experiments, indicating an absence of interparticle contribution to the intensity. The radius of gyration calculated on the basis of Guinier plot was $22.4 \AA$ (Fig. 4A - insert, Table 3).

A pair-distance distribution function, $P(r)$, is characteristic of globular particles, as indicated by the Guinier plot. The $P(r)$, calculated from the scattering data, has a maximum distance $\left(D_{\max }\right)$ of $69.7 \AA$ (Fig. 4B). BlExoPG $R g$ determined on the basis of its $P(r)$ was also $22.4 \AA$ A A Kratky plot of the scattering data showed a well-defined peak, suggesting that BlExoPG is a compact protein (Fig. 4C). Furthermore, Porod-Debye plots $\left(I(q) q^{4}\right.$ versus $\left.q^{4}\right)$ [40] of the scattering data present clear plateaus (Fig. 4D), indicating that the protein lacks disordered regions when in solution.

We constructed the atomic models for the BlExoPG using a protein structure homology-modeling approach $[41,42]$ by combining the crystal structures of GH28 polygalacturonase from Erwinia carotovora ssp. carotovora (EccPG; PDB id: 1BHE) [43] and GH28exo-polygalacturonase from T. maritima (TmPG; PDB id: 3JUR) [44]. One hundred homology models were built and all the models were compared with the BlExoPG experimental scattering curve. In order to choose the most representative model, we evaluated how well the structures
Table 3

SAXS data collection and experimental parameters.

\begin{tabular}{ll}
\hline Data collection parameters & \\
\hline Instrument & B21 beamline (Dimond synchrotron) \\
q-range used in DAM model $\left(\AA^{-1}\right)$ & 0.0095 to 0.3619 \\
Exposure time $(\mathrm{s})$ & $3-\mathrm{s}$ time exposure intervals \\
Concentration & $2 \mathrm{mg} / \mathrm{mL}$ \\
Temperature & $25\left({ }^{\circ} \mathrm{C}\right)$
\end{tabular}

\begin{tabular}{|c|c|c|c|c|c|c|c|}
\hline & $B l \mathrm{Exo} P G$ & $\begin{array}{l}\text { Homol. } \\
\text { Model }\end{array}$ & $1 \mathrm{BHE}$ & 3JUR (A) & 3JUR (AB) & 3JUR (AC) & 3JUR \\
\hline $\begin{array}{c}\mathrm{R}_{\mathrm{g}}(\AA) \text { from } \\
\text { Guinier } \\
\text { plot }\end{array}$ & 22.4 & 21.7 & 20.7 & 22.1 & 40.5 & 29.8 & 45.2 \\
\hline $\begin{array}{l}R_{g}(\AA) \text { from } P \\
\text { (r) function }\end{array}$ & $22.4 \pm 1.3$ & None & None & None & None & None & None \\
\hline $\mathrm{D}_{\max }(\AA ̊)$ & 69.7 & 74.6 & None & None & None & None & None \\
\hline$\chi_{\text {Exp/DAMMIFN }}$ & 0.88 & None & None & None & None & None & None \\
\hline$\chi_{\text {Exp/PDBdatabase }}$ & None & 0.91 & 0.92 & 0.91 & 2.2 & 2.3 & 4.6 \\
\hline No. Molecules & 1 & 1 & 1 & 1 & 2 & 2 & 4 \\
\hline
\end{tabular}

Molecular mass determination

\begin{tabular}{ll} 
MW estimated from SAXS data using SAXSMoW & $\begin{array}{l}44.0 \mathrm{kDa} \\
48.14 \mathrm{kDa}\end{array}$ \\
MW calculated on the basis of the protein amino acid sequence & \\
\hline Software employed & ScÅtter pipelines and ATSAS suite \\
\hline $\begin{array}{l}\text { Primary data reduction and processing } \\
\text { ab initio analysis }\end{array}$ & DAMMIF/DAMMIN \\
Align ab initio models & DAMAVER \\
$3 D$ structure superimposes & SUPCOMB \\
\hline
\end{tabular}

matched the experimental SAXS curve by using the $\chi$-parameter, which measures the quality of the fit between each generated model and the experimental SAXS curve. The scattering curve calculated on the basis of the best homology model has $\chi=0.91$ with the experimental SAXS data. Furthermore, the $P(r)$ curve calculated from the atomic structures of our best homology model reproduced the $P(r)$ distribution calculated from the experimental SAXS data of BlExoPG well (Fig. 4B).

A low resolution envelope of $B$ IExoPG reconstructed from the SAXS data utilizing an $a b$ initio method $(\chi=0.88)$ could be superimposed 


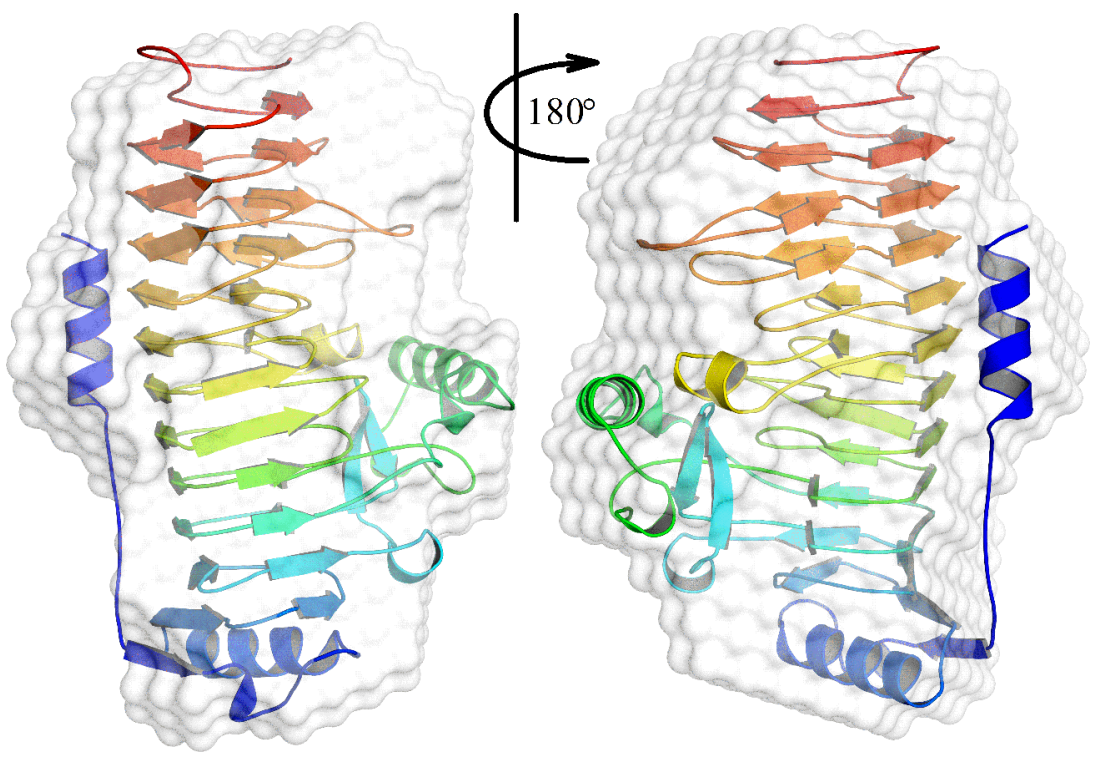

Fig. 5. Low-resolution BlExoPG model. Front and side view of BlExoPG. Monomeric ab initio DAM-derived molecular envelope (gray semi-transparent surfaces) obtained from SAXS data is superimposed with the best homology model. The protein cartoon of the homology model is rainbow-colored from $\mathrm{N}$-terminus (blue) to C-terminus (red). (For interpretation of the references to colour in this figure legend, the reader is referred to the web version of this article.) upon the respective homology model of BlExoPG (Fig. 5 and Table 3). The theoretical scattering profile calculated for the BlExoPG homology model also reproduced the experimental SAXS curve well $(\chi=0.91$, Table 3). It has been previously reported that GH28 PGs can form monomers as well as larger molecular assemblies, such as dimers or tetramers, in solution [43-45]. The EccPG remains monomeric in solution, while the pectin methylesterase from tomatoes can form dimers in solution at higher concentrations of the protein [43,45]. Finally, TmPG has a tetrameric quaternary structure [44].

We compared theoretically computed SAXS scattering curves from the EccPG and TmPG structures (that have 29\% and 49\% sequence identities with BlExoPG, respectively) against experimental BlExoPG SAXS data. For TmPG, the asymmetric unit contains four molecules (A-D), which have two types of interactions [43-45]. The scattering curves for molecule pairs A/C, A/B and A/D were calculated and fitted against the experimental SAXS data with $\chi$ values of 2.2, 2.3 and 4.6, respectively (Table 3 ). Next, the scattering curves for the monomers of TmPG (PDB id: 3JUR, chain A) and EccPG (PDB id: 1BHE; with one molecule in asymmetric unit) were calculated and superimposed upon the experimental SAXS data giving $\chi$ values of 0.91 and 0.92 , respectively (Table 3). Thus, collectively, our SAXS analysis strongly supports the notion that BlExoPG exists as monomers in solution and has a welldefined and rigid globular low resolution shape, closely resembling other GH28 enzymes.

\section{Authors contributions}

DEE and IP designed the experiments. DEE cloned, expressed, purified and characterized the enzymatic activity of BlExoPG. MASK determined the BlExoPG cleavage pattern. MON collected the SAXS data. EAA processed the SAXS data. All authors contributed to the discussions of experimental results and writing of the manuscript.

\section{Funding}

This study was supported by the Fundação de Amparo à Pesquisa do Estado de São Paulo (FAPESP) grants \#2011/20505-4 and \#2015/ 13684-0, and the Conselho Nacional de Desenvolvimento Científico e Tecnológico (CNPq) grants \#405191/2015-4, \#440977/2016-9, \#303988/2016-9 and \# \#158752/2015-5. Danilo E. Evangelista was supported by $\mathrm{PhD}$ fellowship from Coordenação de Aperfeiçoamento de Pessoal de Nível Superior (CAPES).

\section{Acknowledgements}

The authors acknowledge Dr. Robert Rambo and B21 beamline staff at the Diamond Light Source Synchrotron (Didcot, UK) for support with synchrotron data collection.

\section{References}

[1] Kashyap DR, Vohra PK, Chopra S, Tewari R. Applications of pectinases in the commercial sector: a review. Bioresour Technol 2001;77:215-27.

[2] Markovic O, Janecek S. Pectin degrading glycoside hydrolases of family 28: sequence-structural features, specificities and evolution. Protein Eng 2001;14:615-31.

[3] Tapre AR, Jain RK. Pectinases: enzymes for fruit processing industry. Int Food Res J 2014;21:447-53.

[4] Pusic T, Tarbuk A, Dekanic T. Bio-innovation in cotton fabric scouring. Acid Neutral Pectinases FTEE 2015;23:98-103.

[5] Llarch A, Logan NA, Castellvi J, Prieto MJ, Guinea J. Isolation and characterization of thermophilic bacillus spp. from geothermal environments on deception island, south shetland archipelago. Microb Ecol 1997;34:58-65.

[6] Jacobs M, Eliasson M, Uhlén M, Flock JI. Cloning, sequencing and expression of subtilisin Carlsberg from Bacillus licheniformis. Nucleic Acids Res 1985;13:8913-26.

[7] Jenny K, Käppeli O, Fiechter A. Biosurfactants from Bacillus licheniformis: structural analysis and characterization. Appl Microbiol Biotechnol 1991;36:5-13.

[8] Yakimov MM, Timmis KN, Wray V, Fredrickson HL. Characterization of a new lipopeptide surfactant produced by thermotolerant and halotolerant subsurface Bacillus licheniformis BAS50. Appl Environ Microbiol 1995;61:1706-13.

[9] Seo JK, Park TS, Kwon IH, Piao MY, Lee CH, Jong KH. Characterization of cellulolytic and xylanolytic enzymes of bacillus licheniformis JK7 isolated from the rumen of a native korean goat. Asian-Aust J Anim Sci 2013;26:50-8.

[10] Damiano V, Ward R, Gomes E, Alves-Prado H, Da Silva R. Purification and characterization of two xylanases from alkalophilic and thermophilic Bacillus licheniformis 77-2. App Biochem Biotechnol 2006;129:289-302.

[11] Acharya S, Chaudhary A. Optimization of fermentation conditions for cellulases production by bacillus licheniformis MVS1 and bacillus sp MVS3 isolated from indian hot spring. Braz Arch Biol Technol 2012;55:497-503.

[12] Rehman HU, Aman A, Zohra RR, Qader SA. Immobilization of pectin degrading enzyme from Bacillus licheniformis KIBGE IB-21 using agar-agar as a support. Carbohydr Polym 2014;102:622-6.

[13] Rehman H, Aman A, Nawaz M, Qader S. Characterization of pectin degrading polygalacturonase produced by Bacillus licheniformis KIBGE-IB21. Food Hydrocolloids 2015;43:819-24.

[14] Rehman HU, Siddique NN, Aman A, Nawaz MA, Baloch AH, Qader SAU. Morphological and molecular based identification of pectinase producing Bacillus licheniformis from rotten vegetable. J Genet Eng Biotechnol 2015;13:5.

[15] Berensmeier S, Singh S, Meens J, Buchholz K. Cloning of the pelA gene from Bacillus licheniformis $14 \mathrm{~A}$ and biochemical characterization of recombinant, thermostable, high-alkaline pectate lyase. App Microb Biotechnol 2004;64:560-7.

[16] Camilo CM, Polikarpov I. High-throughput cloning, expression and purification of glycoside hydrolases using Ligation-Independent Cloning (LIC). Protein Exp Purif 2014;99:35-42.

[17] Studier FW. Protein production by auto-induction in high-density shaking cultures. Protein Exp Purif 2005;41:207-34.

[18] Miller GL. Use of dinitrosalicylic acid reagent for determination of reducing sugar. 
Anal Chem 1959;31:426-8.

[19] Ovodov Y, Evtushenko E, Vaskovsky V, Ovodova R, Soloveva T. Thin-layer chromatography of carbohydrates. J Chromatogr 1967;26:111-5.

[20] Guinier A, Fournet G, Walker CB. Small angle scattering of X-rays. Phys Today 1955;9:38-9.

[21] Konarev PV, Svergun DI. A posteriori determination of the useful data range for small-angle scattering experiments on dilute monodisperse systems. Int Union Crystallogr J 2015;2:352-60.

[22] Perry JJP, Tainer JA. Developing advanced X-ray scattering methods combined with crystallography and computation. Methods (San Diego, Calif.) J. 2013;593:363-71.

[23] Franke D, Svergun DI. Dammif, a program for rapid ab-initio shape determination in small-angle scattering. J Appl Crystallogr 2009;42:342-6.

[24] Svergun DI. Restoring low resolution structure of biological macromolecules from solution scattering using simulated annealing. Biophysical J 1999;76:2879-86.

[25] Petoukhov MV, Franke D, Shkumatov AV, Tria G, Kikhney AG, Gajda M, et al. New developments in the ATSAS program package for small-angle scattering data analysis. J Appl Crystallogr 2012;45:342-50.

[26] Kozin MB, Svergun DI. Automated matching of high- and low-resolution structural models. J Appl Crystallogr 2001;34:33-41.

[27] Schneidman-duhovny D, Hammel M, Sali A. FoXS: a web server for rapid computation and fitting of SAXS profiles. Nucleic Acids Res 2010;38:W540-44.

[28] Fischer H, Oliveira Neto M, Napolitano HB, Polikarpov I, Craievich AF. Determination of the molecular weight of proteins in solution from a single smallangle X-ray scattering measurement on a relative scale. J Appl Crystallogr 2010;43:101-9.

[29] Jansen EF, Macdonnell LR. Influence of methoxyl content of pectic substances on the action of polygalacturonase. Arch Biochem 1945;8:97-112.

[30] Crelier S, Robert MC, Claude J, Juillerat M. Tomato (Lycopersicon esculentum) pectin methylesterase and polygalacturonase behaviors regarding heat- and pressure-induced inactivation. J Agric Food Chem 2001;49:5566-75.

[31] Mohamed SA, Christensen TMIE, Mikkelsen JD. New polygalacturonases from Trichoderma reesei: characterization and their specificities to partially methylated and acetylated pectins. Carbohydr Res 2003;338:515-24.

[32] Rashad MM, Abdou HM, Shousha WGH, Ali MM, El-Sayed NN. Purification and characterization of extracellular polygalacturonase from Pleurotus ostreatus using citrus limonium waste. J Appl Sci Res 2010;6:81-8.

[33] Kobayashi T, Higaki N, Suzumatsu A, Sawada K, Hagihara H. Purification and properties of a high-molecular-weight, alkaline exopolygalacturonase from a strain of Bacillus. Enzyme Microb Technol 2001;29:70-5.

[34] Kluskens LD, Van Alebeek GWM, Walther J, Voragen AGJ, Vos WM, Van der Oost J. Characterization and mode of action of an exopolygalacturonase from the hyperthermophilic bacterium Thermotoga maritima. FEBS J 2005;272:5464-73.

[35] Parisot J, Langlois V, Sakanyan V, Rabiller C. Cloning expression and characterization of a thermostable exopolygalacturonase from Thermotoga maritima. Carbohydr Res 2003;338:1333-7.

[36] Kaur G, Kumar S, Satyanarayana T. Production, characterization and application of a thermostable polygalacturonase of a thermophilic mould Sporotrichum thermophile Apinis. Bioresour Technol 2004;94:239-43.

[37] Garg G, Singh A, Kaur A, Singh R, Kaur J, Mahajan R. Microbial pectinases: an ecofriendly tool of nature for industries. 3 Biotechnology 2016;6:47-60.

[38] Novozymes A/S, Bagsvaer (DK). Pectate lyases. United States of America patent, US 6,399,351 B1. Appl number 09/526,416. 2002.

[39] Novozymes A/S, Bagsvaer (DK). Pectate lyases. United States of America patent, US 6,284,524 B1. Appl number 09/546,762. 2001.

[40] Rambo RP, Tainer JA. Characterizing flexible and intrinsically unstructured biological macromolecules by SAS using the Porod-Debye law. Biopolymers 2011;95:559-71.

[41] Webb B. Sali A. comparative protein structure modeling using MODELLER. Curr Protoc Bioinform 2014;47(5.6). 1-5.6.32.

[42] Webb B, Sali A. Protein structure modeling with MODELLER. Methods Mol Biol 2014;1137:1-15.

[43] Pickersgill R, Smith D, Worboys K, Jenkins J. Crystal Structure of Polygalacturonase from Erwinia carotovora ssp carotovora. J Biol Chem 1998;273:24660-4.

[44] Pijning T, van Pouderoyen G, Kluskens L, van der Oost J, Dijkstra BW. The crystal structure of a hyperthermoactive exopolygalacturonase from Thermotoga maritima reveals a unique tetramer. FEBS Lett 2009;583:3665-70.

[45] Vovk I, Simonovska B. Isolation of tomato pectin methylesterase and polygalacturonase on monolithic columns. J Chromatogr A 2007;1144:90-6.

[46] Klerzyme 150. DSM Food Specialties, http://www.centerchem.com/Products/ klerzyme-150/. [Accessed 02 August 2017].

[47] Pectinase PE-500. Jiangsu Boli Bioproducts Co. Ltd, https://www.alibaba.com/ product-detail/Pectinase-Enzyme-for-Juice-Processing_60645649562.html. [Accessed 02 August 2017].

[48] Pectinase. Parchem - Fine \& Specialty Chemicals, http://www.parchem.com/ chemical-supplier-distributor/Pectinase-007378.aspx. [Accessed 02 August 2017].

[49] Pectinase. Biocon, http://biocon.es/en/products/commercial-enzymes/technicaland-safety-data-sheets/. [Accessed 02 August 2017].

[50] Polygalacturonase, Biocon, http://biocon.es/en/products/commercial-enzymes/ technical-and-safety-data-sheets/. [Accessed 02 August 2017].

[51] Macerozyme R-10. Duchefa Biochemie B.V, https://www.duchefa-biochemie.com/ product/details/number/M8002/name/macerozyme-r-10. [Accessed 02 August 2017]. 